\title{
Logical Training for College Student for Reducing Academical Stress
}

\author{
Junming Chen \\ University of California, Los Angeles, Los Angeles, United States
}

Email: lynnlin@xyzrgroup.com

\begin{abstract}
In recent years, American college students tend to fall into anxiety easily, and one of the main source of stress is academic performance. However, there are lots of treatments to release stress by sports and music, but few studies mentioned the function of training Mathematical logic, that may be applied to college lives improvement. Therefore, the purpose of this study is to establish preliminary evidence for the effect of strengthening mathematical thinking ability on the academic stress of young college students.
\end{abstract}

\section{Keywords: Stress, Students, Mental Health, Mathematical Education, Geometry.}

\section{INTRODUCTION}

The number of reports of the school Counseling Center even increased by more than $110 \%$, while the data of visits increased by $231 \%$. Of the reports available, academic achievement was the most stressful factor for students.[1]

In addition to studying, many studies have explored the use of exercise and music as a therapy for psychological stress. However, there has been little research into whether developing mathematical logic has a stress-reducing effect on college students, and even a century of changes in North American Math education, including the New Math movement, have involved few mathematicians. [2] Nonetheless, mathematics and logic education itself, the foundation of the vast majority of subjects, also occupy a large proportion of students' academic content; Therefore, it can be said that the research on mathematics education has great potential in improving students' learning efficiency, improving students' academic pressure, and training students' comprehensive logic ability. And now the research progress is gradually advancing, although it has not attracted widespread attention, several studies before showing the potential of the logic training can work on releasing stress.

\section{METHOD}

After searching with the keywords "Academic Stress"“Mathematics Education"and "Mental Health" in Google Scholar and PubMed, I selected papers with clear arguments to summarize and organize their key information. Finally, utilizing the materials quoted in the previous project on campus I took before and summarized them together with the selected articles, datas and results can finally be analyzed and tested.

\section{ACADEMIC STRESS OF COLLEGE STUDENTS}

According to James Milgram, a professor of mathematics at Stanford University, as a result of repeated changes over the last century to cut mathematics, textbooks have eliminated almost all geometry, statistics, and most algebra. This dramatic decline in standards has left many students unable to keep up with college STEM education. Mathematics itself is particularly closely related to other science subjects, so this low standard itself puts most students under enormous academic pressure in all science subjects.[2] In addition, the low standard of teaching materials and content requirements for mathematics education will also affect the work efficiency and ability of mathematics education workers, especially the basic education workers. Professor Goya pointed out that in the past, one of the elements of the quality of mathematics education was the quality of teachers. However, in the case of the general reduction of the requirements of various indicators, the quality of many teachers in mathematics basic education is also constantly decreasing, which directly leads to many students being unable to complete the excessive, and unable to adapt to college courses. Even in the past 30 years, Michigan state university freshmen in between $25 \%$ and $30 \%$ are arranged in the tutorial on the mathematics curriculum, even if they are relative to previous students have more time for the elementary education of mathematics, but according to the observation and detection of data, most of the student's mathematical ability and thinking ability instead of performance worse and worse. [3] Poorer academic 
level and thinking ability will directly lead to more effort and pressure for students to carry out academic work of the same difficulty as before. Therefore, to some extent, this kind of low standard and inefficient academic requirements and content arrangement is one of the main sources of student pressure.

Confronted with a large amount of academic work, a number amount of college students tend to disrupt their original life schedule and even engage in a variety of behaviors that are seriously harmful to their health, such as drinking alcohol and exposure to different kinds of drugs.[4] However, according to various studies in recent years, students' self-regulation is generally regulated by the incentive system, and the corresponding negative behavior can not provide positive motivation, and students' academic life will be more inclined to fall into a vicious circle. A more effective education model should guide students to be aware of cognitive and metacognitive strategies, and enable students to form self-regulation under the leading effect of self-efficacy. However, much content planning in the existing system has obvious defects and cannot provide positive incentives for students, especially in mathematics education. [5] In a study specifically focused on Math anxiety, Professor Luttenberger pointed out that there was a positive correlation between Math anxiety and students' self-evaluation in different regions. After his team collected and processed data, it was found that Math anxiety directly affected students' learning efficiency in the long term, resulting in the frequent occurrence of procrastination behavior and reduced students' attention. Data show that Math anxiety also plays a significant role in students' life planning and self-cognition. Students who are not properly guided will have a deeper degree of anxiety in gender-related self-cognition, and math anxiety itself will also limit the vocational choices of many students. Under the influence of anxiety, many students limit their career choices and even influence their choice of schools and majors, which directly affects the enrollment rate of universities. The impact of Math anxiety has been shown to be crucial in avoiding enrollment in related fields such as science, technology, and engineering. [6]

Unlike alcohol and marijuana, which many students use more for self-relaxation, many students even continue to use neurostimulants like Ritalin and Adderall, increasing their stress and creating a vicious cycle; This phenomenon is more common in more competitive schools.[7] A study by Pino's team reported an increase in drug abuse due to academic pressure over the past decade, with nearly 30 percent of volunteers in a sample of individual locations reporting that they had engaged in illicit drug abuse to improve academic performance. However, it is important to note that drug abuse is often accompanied by alcohol and tobacco abuse, and vice versa. In an environment of the continuous vicious cycle, students caught in it are likely to become increasingly unable to balance their lives. However, if students have low academic pressure or strong academic moral sense, no matter they have social needs or encounter academic pressure, they are more likely not to engage in substance abuse behavior under any circumstances.[8]

\section{TRAINING FOR MATHEMATICAL LOGIC AND ACADEMIC PERFOR- MANCE}

After Mathematics is the foundation of most science subjects, and it is also used to develop students' logic ability and learning ability. The study also showed a positive correlation between academic ability and math ability, both for tutors and students.[9]

Education departments in many countries have tried to strengthen the training of logic in their educational systems, such as the New Math movement in the last century, but as Professor James Milgram pointed out, that reform was too abstract and too algebraic, and the important reforms of the last century themselves involved very few mathematicians. There is no good design textbook to guide students to train mathematical logic thinking.[2]

In Asia, where both math and academic scores are high, textbooks start with translations and revisions of a math textbook by Russian mathematician Andrey Kolmogorov, and then are modified and refined to make the logic training more appropriate for students who, studies show, have relatively strong overall academic abilities. These students generally have less academic pressure in European and American universities, so it is feasible to reduce academic pressure by developing stronger learning abilities.[9] For students who have a particular need for math anxiety, which in some state universities accounts for as much as $30 \%$ of the total number of students, improved learning ability can not only reduce stress; As mentioned above, the most important benefit for students may not only be improved attention and reduction of procrastination behavior but also all-round improvement of learning ability, thus obtaining a wider choice of majors and career prospects, as well as a more comprehensive and objective self-evaluation. [6] This is far more beneficial in the long run than mere stress reduction.

\section{LOGICAL TRAINING CONTENTS AND THE PSYCHOLOGICAL EFFECTS ON STUDENTS}

\subsection{Better Academic Performance and Less Academic Stress}

Of all the ways of mathematical study, the understanding of geometry has always been the simplest, the most important, and the most direct way for logical training. After a quick training period of Geometry Learning Videos (VPG), more than $75 \%$ of students can improve their Geometry Thinking Level (PBG) significantly, which plays an important role in understanding and 
learning most other science subjects; Thus, science subjects, especially Physics, that most students take can get much better performance after this simple logical training.[10] However, the training process may still need to improve in different aspects, to form a more comprehensive and efficient training system, for the improvement of $25 \%$ student remaining.

Moreover, while many studies have shown a positive correlation between mathematical ability and scores of other subjects, some studies have pointed out that understanding and thinking ability of geometry and graphics are the most important and indispensable. The training of geometry and figures has always been the foundation of logic training, as evidenced by a century of iterative refinement of intelligence tests. At present, mathematics education is more inclined to the training of calculation ability rather than logical thinking. Therefore, professor Planinic indicates that adding simple thinking ability training can effectively improve the learning ability of other science subjects on the basis of the original mathematical ability without a large amount of new knowledge.[11] In Planinic's study, he went into more detail about the effectiveness and specific applications of training. When studying students' understanding of abstract concepts in physics teaching, students who have been trained in spatial thinking can complete understanding of most data graphs more quickly and accurately. In this process, the test of students for abstract concepts and data understanding ability, trained students, can perform better; They can more easily find connections between abstract concepts and concrete objects, and can more easily analyze the meaning of data on images.

Besides the logical ability training of geometry, the training of the concept of abstract formula and learning strategies and ideas will also be of great help to the learning efficiency of students, which can greatly reduce the educational resources input, but more efficient understanding and application. Professor Susac believes that this is why physics students in the study were more efficient than other students, even 35 percent more efficient than psychology students on average.[12]In the Susac experiment, the reaction and comprehension abilities of science major students and non-science major students in various topics were compared. It is found that in the experimental group and the control group, the only ability that has a big gap with graphics among all abilities is the understanding of space and graphics-related content. This also explains why numerical-graphic teaching strategies are often more effective.

With a relatively great improvement in learning efficiency, academic stress can be reduced to a large extent and students also have more opportunities to achieve better academic performance.

\subsection{Divert Attention Appropriately and De- velop Interest in Logic Training}

When students are under pressure, they will not only seek outside help, but also actively take several other effective ways: to shift their attention, or to adjust their mentality -- change their way of seeking positive motivation.[13] Training logical thinking skills by opening up new areas, such as adding targeted geometry courses, can not only relieve the stress but also the experimental results show that students' feedback to the new course is mostly positive. [14] This course also takes into account the characteristics of mathematical logic training mentioned above, which has a positive effect on the beginning of engineering and science learning content. At the same time, the training of abstract thinking and practical application ability, especially for the understanding and learning of physical content has a great positive effect. [11]

The logic training itself can also be a kind of selfinteractive game and has a lot of flexibility. Although any training can be stressful for students, most of the questions can be fun and self-training if they are properly designed. Like most games, there is an inherent reward system for the students involved, and the students can also receive positive emotional feedback.[15] Although it didn't provide the same peaks of positive emotional feedback as video games or sports that most students are exposed to today, it did provide more stable emotional feedback, lower blood pressure, and had a longer-lasting effect at times. At the same time, in addition to the reduction of physiological stress, this mode of guiding students to know cognitive and metacognitive strategies is more in line with the efficient self-regulation training learning mode found by Arabzadeh's team. Data show that self-regulation can directly explain nearly $25 \%$ variance of academic anxiety, while self-efficacy indirectly explains nearly $30 \%$ variance of academic stress, which will greatly reduce students' academic anxiety. [5] The fact that this pressure is a major source of stress in students' lives today also makes it possible for this strategy to be greatly reduced by unilaterally adding simple content without changing the general framework of education.

\section{CONCLUSION}

Current data suggest that increased training in mathematical logic has a positive impact on academic performance and can reduce stress levels in college students. This is a teaching reform strategy that can have a positive impact on many subjects without changing other curriculum content. The program has the potential to significantly reduce students' academic stress, stabilize their physical and mental health, and provide students with more possibilities for future development. However, specific relevant studies are not abundant. Apart from some studies on the influence of geometry and topology on other courses, and some studies on the correlation of mathematical logical thinking ability on students' comprehensive learning efficiency, researchers in the past paid more attention to the formulation of rules such as grades and examination standards. The study, therefore, 
needs further examination and testing. Further research is needed to examine the extent to which different intensities of training meet the needs of students of different academic abilities, to confirm the efficacy of mathematical logic training, to improve the training system, and to test whether it is appropriate for inclusion in university syllabuses.

\section{REFERENCES}

[1] Beiter R, Nash R, McCrady M, Rhoades D, Linscomb M, Clarahan M, Sammut S. The prevalence and correlates of depression, anxiety, and stress in a sample of college students. J Affect Disord. 2015 Mar 1;173:90-6. doi: 10.1016/j.jad.2014.10.054. Epub 2014 Nov 8. PMID: 25462401.

[2] Milgram, R. J., \& Stotsky, S. (2013). Lowering the bar: How common core math fails to prepare high school students for STEM Pioneer Institute for Public Policy Research. Retrieved from http://www.uaedreform.org/wp-content/uploads/2000/01/Lowering the Bar.pdf

[3] Goya, S. (2006). The critical need for skilled math teachers. Phi Delta Kappan, 87(5), 370-372. Retrieved from http://access.library.miami.edu/login?url=https://www.proquest.com/schol arly-journals/critical-need-skilled-math-teachers/docview/218473280/se-2?accountid=14585

[4] Lund HG, Reider BD, Whiting AB, Prichard JR. Sleep patterns and predictors of disturbed sleep in a large population of college students. J Adolesc Health. $2010 \quad$ Feb;46(2):124-32. doi: 10.1016/j.jadohealth.2009.06.016. Epub 2009 Aug 3. PMID: 20113918.

[5] Arabzadeh, M., Nikdel, F., Kadivar, P., Kavousian, J., \& Hashemi, K. (2012). THE RELATIONSHIP OF SELF-REGULATION AND SELF-EFFICACY WITH ACADEMIC STRESS IN UNIVERSITY STUDENTS. International Journal of Education and Psychology in the Community, 2(2), 102-113. Retrieved from http://access.library.miami.edu/login?url=https://www.proquest.com/schol arly-journals/relationship-self-regulation-efficacywith/docview/2220696486/se-2 accountid=14585

[6] Luttenberger, S., Wimmer, S., \& Paechter, M. (2018). Spotlight on math anxiety. Psychology Research and Behavior Management, 11, 311-322. doi:http://dx.doi.org/10.2147/PRBM.S141421

[7] McCabe SE, Knight JR, Teter CJ, Wechsler H. Nonmedical use of prescription stimulants among US college students: prevalence and correlates from a national survey. Addiction. 2005 Jan;100(1):96106. doi: 10.1111/j.1360-0443.2005.00944.x. Erratum in: Addiction. 2005 Apr;100(4):573. PMID: 15598197.

[8] Pino, N. W., Tajalli, H., Smith, C. L., \& DeSoto, W. (2017). Nonmedical prescription drug use by college students for recreational and instrumental purposes: Assessing the differences. Journal of Drug Issues, $\quad 47(4), \quad 606-621$. doi:http://dx.doi.org/10.1177/0022042617714459

[9] Stewart, Vivien. (2009) China and U.S. Can Swap Ideas About Math and Science, http://access.library.mi-

ami.edu/login?url=https://search.proquest.com/doc view/218485945? accountid=14585

[10] Abu, M.S., \& Abidin, Z.Z. (2013). Improving the Levels of Geometric Thinking of Secondary School Students Using Geometry Learning Video based on Van Hiele Theory. International Journal of Evaluation and Research in Education, 2, 16-22.

[11] Planinic, M., Milin-Sipus, Z., Katic, H., Susac, A., \& Ivanjek, L. (2012). COMPARISON OF STUDENT UNDERSTANDING OF LINE GRAPH SLOPE IN PHYSICS AND MATHEMATICS. International Journal of Science and Mathematics Education, 10(6), 1393-1414. https://doi.org/10.1007/s10763-012-9344-1

[12] Susac, A., Bubic, A., Kazotti, E., Planinic, M., \& Palmovic, M. (2018). Student understanding of graph slope and area under a graph: A comparison of physics and nonphysics students. Physical Review. Physics Education Research, 14(2), 020109. https://doi.org/10.1103/PhysRevPhysEducRes.14.020109

[13] Phillips SP, Reipas K, Zelek B. Stresses, Strengths and Resilience in Adolescents: A Qualitative Study. J Prim Prev. 2019 Dec;40(6):631-642. doi: 10.1007/s10935-019-00570-3. PMID: 31659580.

[14] Kolingerova, I. (2008). Computational geometry education for computer graphics students. Computer Graphics Forum, 27(6), 1531-1538. doi:http://dx.doi.org/10.1111/j.14678659.2008.01172.x

[15] Porter AM, Goolkasian P. Video Games and Stress: How Stress Appraisals and Game Content Affect Cardiovascular and Emotion Outcomes. Front Psychol. 2019 May 7;10:967. doi: 10.3389/fpsyg.2019.00967. PMID: 31133924 ; PMCID: PMC6524699. 